\title{
Social determinants and cardiovascular disease mortality in Panama, 2012-2016
}

Luis Quiel', Ilais Moreno Velásquez ${ }^{1}$, Beatriz Gómez ${ }^{1}$, Jorge Motta ${ }^{1,2}$ and Víctor Herrera-Ballesteros ${ }^{1,3^{*}}$ (D)

\begin{abstract}
Background: The aims of this study were to determine the geographic and time variation of social determinants of health (SDH) and cardiovascular disease (CVD) mortality in Panama from 2012 to 2016, and to identify which of the SDH has the strongest correlation with a socioeconomic index (SEI).

Methods: We conducted an ecological study obtaining mortality from the National Mortality Register and socioeconomic variables derived from the National Household Survey (NHS). The International Classification of Diseases 10th revision codes 120-125 and 160-169 were used for ischemic heart disease (IHD) and stroke, respectively. Standardized age-adjusted mortality rates were calculated by direct method. Mortality rates and socioeconomic variables were evaluated together in a panel data model. A SEI was developed from factorial analysis by principal components with a polychoric correlation matrix. Provinces and regions were categorized in tertiles according to median value of the SEI score.

Results: The NHS evaluated an average of 15,919 households per year. The mean of age throughout the study period was 41 years. The average monthly income increased, from US\$ (SD) 331.94 (5.38) in 2012, to 406.24 (5.81) in 2016, whereas the social security health coverage remained in a range of $57-58 \%$. The mean number of school years was twelve. Significant geographical and temporal variations in social determinants and mortality rates were observed throughout the country. Colon, categorized in the middle tertile according to the SEl, presented higher IHD mortality rates. Darién (in the lowest SEl tertile) Colón and Herrera had higher stroke mortality rates. The SEI categorized indigenous territories in the lowest tertile. Total years of education was the strongest correlated variable with the SEl, when we excluded the population living in indigenous territories. However, when this population was included, social security coverage had the strongest correlation with the SEl.
\end{abstract}

Conclusion: We observed geographical and temporal disparities in SDH and CVD mortality rates. Further epidemiological studies are warranted in the provinces of Colón, Darien, Herrera and Los Santos to explore in-depth the higher CVD mortality rates observed in these provinces.

Keywords: Social determinants, Cardiovascular mortality, Panama

\section{Background}

Cardiovascular disease (CVD) claimed 17.7 million lives in 2015, and this represented approximately $31 \%$ of all global deaths [1]. From 2006 to 2016, despite efforts in prevention, screening and treatment, CVD remains the main cause of death in most countries [2,3]. Nevertheless, in this same period of time, global death rates from

\footnotetext{
*Correspondence: vherrera@gorgas.gob.pa

${ }^{1}$ Gorgas Memorial Institute for Health Studies, Panama City, Panama

${ }^{3}$ Department of Research and Health Technology Assessment." Gorgas

Memorial Institute for Health Studies, Panama City, Panama

Full list of author information is available at the end of the article
}

CVD decreased by $14.5 \%$ [2]. In 2016, $85.1 \%$ of all CVD deaths were produced by ischemic heart disease (IHD) and stroke combined [2].

Recently, a multi cohort study and meta-analysis showed that a low socioeconomic status had a comparable effect in individual's health than the traditional risk factors [4]. These findings suggest that socioeconomic adversity should be considered as a modifiable risk factor in local and global strategies directed at reducing premature mortality. Studies conducted in European countries have

(c) The Author(s). 2019 Open Access This article is distributed under the terms of the Creative Commons Attribution 4.0 International License (http://creativecommons.org/licenses/by/4.0/), which permits unrestricted use, distribution, and reproduction in any medium, provided you give appropriate credit to the original author(s) and the source, provide a link to the Creative Commons license, and indicate if changes were made. The Creative Commons Public Domain Dedication waiver (http://creativecommons.org/publicdomain/zero/1.0/) applies to the data made available in this article, unless otherwise stated. 
consistently demonstrated the contribution of social inequalities to CVD incidence and mortality $[5,6]$.

In Latin America (LA), CVD is responsible for 33.7\% of total mortality [7]. In the last decade, important social and economic changes have occurred in this region, however, according to the World Economic Forum and the International Monetary Fund, LA remains one of the most unequal region worldwide [8]. To the best of our knowledge, studies that explore the social determinants of health in CVD incidence and mortality are scarce in Central America.

Panama is an upper-middle-income country located in Central America with a population of $>4$ million. The country is politically divided in ten provinces (Bocas del Toro, Coclé, Colón, Chiriquí, Darién, Herrera, Los Santos, Panama, Veraguas and West Panama) and five indigenous territories (Emberá-Wounaan, Guna Yala, Ngöbe-Buglé, Kuna de Madugandí and Kuna de Wargandí - the first three are categorized as provinces). According to the latest estimates, indigenous peoples represent $12 \%$ of the total population in the country [9]. CVD mortality trends have declined in recent years [10], yet CVD is still the leading cause of death, responsible for $28 \%$ of national mortality [11].

Even though Panama has been one of the fastest growing economies in the world in the last 10 years, socioeconomic inequalities persist, especially in indigenous territories. The World Bank estimated a Gini index of 50.8 in 2015, ranking Panama as a highly unequal country [12]. Results from the Multidimensional Poverty Index (MPI) indicated that $19.1 \%$ of the Panamanian population live in a multidimensional poor household [13]. Furthermore there is increasing evidence of the association between social determinants of health $(\mathrm{SDH})$ and non-communicable diseases in Panama. Observational studies have shown that the lack of social security coverage in patients with gastric cancer is an independent risk factor for all-cause mortality; monthly family income has an inverse association with chronic kidney disease and monthly individual income less than US\$ 100 has a strongest correlation to mortality due to diabetes mellitus (DM) [14-16]. However, the SDH in relation to CVD mortality in Panama remains to be explored.

The aims of this study were to: (i) determine the geographic and time variation of SDH and CVD mortality and (ii) identify which of the social determinants has the strongest correlation with a socioeconomic status index.

\section{Methods}

We designed an ecological study in an attempt to determine if there was any relation between SDH (defined as years of education, social security coverage and monthly income) and mortality due to CVD in Panama. The data were obtained from the household survey (HS) and the National Mortality Register (NMR); both derived from the National Institute of Statistics and Census (INEC, from its Spanish translation Instituto Nacional de Estadística y Censo).

Data were analyzed at the provincial level except for the province of Panama, which was divided into four regions. In total, we studied eight provinces (Bocas del Toro, Coclé, Colón, Chiriquí, Darién, Herrera, Los Santos and Veraguas) and four regions (Panama, San Miguelito, West Panama, East Panama).

\section{National Mortality Register}

We conducted a registry-based analysis of mortality due to CVD, from the years 2012 to 2016. Several studies evaluated the data obtained from the Panamanian civil registration and vital statistics and classified it as high quality $[17,18]$. CVD was defined and coded, following the tenth revision of the International Classification of Diseases (ICD-10). ICD-10 codes I20-I25 and I60-I69 were utilized for IHD and stroke, respectively.

\section{Household survey}

The HS is a tool used to identify the employment status and socioeconomic conditions of the general population. It is widely used by governments to measure the characteristics of the working market and report unemployment. The World Bank, The International Labour Organization and the Oxford Poverty and Human Development Initative use the HS data to measure inequality calculate unemployment trends and construct the MPI, respectively. Other studies concerning reproductive, maternal, newborn, and child health have used HS as the primary data source to evaluate coverage indicators $[19,20]$.

In Panama, the HS has been applied biannually since 1963 (March and August) [21]. Households are randomly selected from the census performed in the country with the aim to be representative by provinces. Households are defined as the location used by a family or a group of people, with or without bonds, which share a unit or a person that lives alone.

The data is collected through person-in-person interviews, including all the members of the household at the moment of the interview and the questions are structured to correspond to the information of the week prior the interview. We analyzed all the data of surveys within each household, and thus, number of study participants may vary per year. Annually, 25\% of households are replaced whereas $75 \%$ of households are revisited 4 times before they are replaced. In order to capture part of the economically active population, the reference period is extended to 6 months explaining why the survey is applied biannually. In Panama, March is a summer month 
where labor market widens, primarily because of seasonal employment and the beginning of the school year. Therefore, in the present study, we utilized the data obtained in August for the time frame 2012-2016, as March may not represent the market behavior compared to other months. An average of 15,919 households was surveyed per year. Since we aimed to address the economically active population, study participants below 15 years of age were excluded $(n=64,202)$. Study participants with missing data for monthly income $(n=73)$ and years of education $(n=122)$ were further excluded. Thus, a total of $n=154,019$ study participants were enrolled in the present study.

The data utilized for the present study is in the public domain and did not contain sensitive information (anonymous secondary data), consequently no ethics approval was required. Permission to have access to the variables utilized from the Household survey was obtained from the National Comptroller (Contraloría General de la República), head of the National Institute of Statistics and Census.

\section{Social determinants of health variables}

Monthly income was analyzed as a continuous variable and defined as the total income an individual received per month in US dollar (\$), including monetary and species earnings, subsidies and grants (the national currency is the Panamanian balboa, however it is pegged with the US dollar at par). It included primary income and the income earned with other economic activities. Social security coverage was categorized as the access to public social security health services, represented as contributor (active worker), beneficiary, retired, pensioner (permanent disability), retired or pensioner from another country and with no coverage. We dichotomized the variable as having or not social security coverage. Years of education were explored as a continuous variable, specifying the maximum number of years of education reached. The education in Panama is characterized in three levels: basic general education, middle education and higher education. Basic general education is compulsory and consists of a total of 11 years, including preschool, elementary and middle school. Middle education consists of an additional 3 years and is diversified in general, pedagogical and technical education. Higher education is subdivided in university and non-university education. Special education is imparted to children with limiting mental or physical conditions.

\section{Statistical analysis}

Dichotomic variables were expressed as percentages and quantitative variables as mean and standard deviations (SD). Estimates were weighted to represent the total population of Panama per province and regions. The expansion factor was calculated and provided by the INEC.

Specific mortality rates for IHD and stroke were calculated separately for each year, province and sex, adjusted by age, based on the 2010 national census estimates and projections of the population per province and region. These mortality rates were standardized by direct method, using the World Health Organization (WHO) standard population. The groups were categorized in 5 -year age groups; however, we reported specific mortality rates from the population aged 35 to 79 years.

To determine if there were changes throughout the years (within variation) and provinces/regions (between variation), the mortality rates and socioeconomic variables were evaluated together in an econometric analysis based on panel data models. The analysis was performed separately for IHD and stroke and by sex. Due to a high underreporting in mortality data, indigenous territories were not included in the panel data analysis [22]. The data was described, summarized and sorted for data panel analysis. The Durbin-Wu-Hausman test was applied to choose between the fixed and random effect models. The Breusch Pagan Lagrange Multiplier test was implemented to choose between random effect and pooled models. The results of this test suggested that a pooled model regression was not suitable. Moreover, within and between variations in standard deviation were found for IHD and stroke.

Because of these findings, socioeconomic variables were merged in a polychoric correlation matrix in order to perform a factor analysis by principal components. Three factors were introduced in the analysis. The common factor was extracted by the principal-component method and then an orthogonal varimax rotation was done in order to distribute the factor loadings. A Kaiser-Meyer-Olkin test was performed to measure how suitable the data was for factor analysis. This factor was predicted for each value and then a SEI was obtained per province/region. Provinces and regions were categorized in tertiles according to the value of its SEI score median.

Analysis were performed in Microsoft Excel 2013 and in Stata IC version 14.0.

\section{Results}

Table 1 summarizes the baseline characteristics of the HS and the CVD mortality rates in the study period. The mean of age throughout the years of study was 41 years. The monthly income increased, from US\$ (SD) 331.94 (5.38) in 2012, to 406.24 (5.81) in 2016 whereas the social security coverage remained in a range of $57-58 \%$. The mean years of education in the study population was twelve years. After exclusion of surveys from indigenous 
Table 1 Distribution of baseline characteristics in the Household Survey and Cardiovascular Disease mortality rates in Panama, 2012-2016

\begin{tabular}{|c|c|c|c|c|c|}
\hline & 2012 & 2013 & 2014 & 2015 & 2016 \\
\hline \multicolumn{6}{|l|}{ Household Survey } \\
\hline Households surveyed & 16,143 & 16,143 & 16,658 & 15,326 & 15,326 \\
\hline Total of surveys & 45,636 & 44,237 & 43,719 & 42,396 & 42,233 \\
\hline Study population $\geq 15$ years & 31,586 & 30,885 & 30,774 & 30,324 & 30,450 \\
\hline Weighted population $\geq 15$ years & $2,659,822$ & $2,719,844$ & $2,782,076$ & $2,846,612$ & $2,909,973$ \\
\hline Age, mean (SD) & $40.4(0.11)$ & $40.6(0.13)$ & $40.8(0.12)$ & $41.1(0.13)$ & $41.0(0.13)$ \\
\hline Monthly income, mean (SD) & $331.9(5.38)$ & $349.8(6.36)$ & $364.6(5.45)$ & $397.9(7.33)$ & $406.3(5.81)$ \\
\hline Access to social security (\%) & 58 & 57 & 56 & 57 & 57 \\
\hline Years of education, mean (SD) & $11.9(0.03)$ & $11.9(0.36)$ & $11.9(0.03)$ & $12.1(0.03)$ & $12.2(0.04)$ \\
\hline Study population $\geq 15$ years excluding indigenous territories & 29,450 & 28,917 & 28,878 & 28,516 & 28,649 \\
\hline Weighted population $\geq 15$ years excluding indigenous territories & $2,530,350$ & $2,589,545$ & $2,650,919$ & $2,714,565$ & $2,777,312$ \\
\hline Age, mean (SD) & $40.6(0.12)$ & $40.7(0.13)$ & $41.0(0.13)$ & $41.3(0.13)$ & $41.2(0.13)$ \\
\hline Monthly income, mean (SD) & $346.3(5.63)$ & $365.5(6.65)$ & $380.6(5.69)$ & $414.4(7.66)$ & $422.6(6.06)$ \\
\hline Access to social security (\%) & 61 & 60 & 59 & 59 & 59 \\
\hline Years of education, mean (SD) & $12.2(0.03)$ & $12.2(0.04)$ & $12.3(0.03)$ & $12.4(0.03)$ & $12.5(0.04)$ \\
\hline \multicolumn{6}{|l|}{ National Mortality Register } \\
\hline Mortality rate IHD ( $\times 100,000$ inhabitants $)$ & 62.8 & 63.8 & 62.6 & 51.1 & 48.2 \\
\hline Mortality rate stroke $(\times 100,000$ inhabitants $)$ & 45.7 & 47.1 & 46.8 & 44.2 & 46.7 \\
\hline
\end{tabular}

Missing data: monthly income $(n=73)$, years of education $(n=122)$

territories, we observed higher percentages of social security coverage and monthly income. Overall, higher mortality rates for IHD $(63.8$ per 100,000$)$ and stroke $(47.1$ per 100,000) were observed in 2013 (Table 1).

\section{National Mortality Register}

From 2012 to 2016, 15,661 deaths were attributed to CVD (IHD $n=8144$ and stroke $n=7517$ ). As shown in Fig. 1 (men), standardized and age-adjusted specific mortality rates $(\times 100,000$ inhabitants) for IHD (Panel A) were higher in Colón for all the years, [2012 (151.9), 2014 (116.8), 2015 (112.1), 2016 (95.3)], except in 2013 (Darién 144.3). Likewise, in women (Fig. 2, Panel A), Colon presented the highest IHD mortality rates 66.2 and 58.8 ( $\times$ 100,000 inhabitants) in 2012 and 2015, respectively. The region of San Miguelito had the highest IHD mortality rates in women (71.9 and 64.7) in 2013 and 2016.

In men, the provinces with the highest mortality rates $(\times 100,000)$ due to stroke (Fig. 1, Panel B) were Colón (89.4 in 2012), Coclé (81.3 in 2013), Herrera (105.2 in 2014), Darién (96.7 in 2015) and the region of San Miguelito (76.5 in 2016). In women, compared to other provinces (Fig. 2, Panel B), Herrera presented higher stroke mortality rates in 2013 (59.4) and 2015 (50.5), whereas Los Santos had the highest mortality rate in 2016 (70.6).

\section{Household survey}

Additional file 1 presents the baseline characteristics of socioeconomic determinants in the HS per region and year. Compared to other regions, the indigenous territories and Darién had the most limited access to social security (4-15\% and $17-22 \%$, respectively), followed by East Panama region (32-42\%). Panama region and San Miguelito region had the highest monthly incomes whereas the population of Darién (except for 2014) had the lowest mean of monthly income (below US\$215.00).

Only the study population of the province of Panama (Panama, San Miguelito and West Panama) and the province of Colón achieved the compulsory years of education in the study period (mean). Overall, years of education were higher in women compared to men in all the regions for all the years (except for indigenous territories); however, average monthly income was higher in men doubling women's monthly income.

The data panel analysis assessed temporal and geographical changes. As shown in Additional file 2, there were higher variations in all the socioeconomic variables and in IHD mortality in men throughout the provinces and regions (between). Similarly, higher variations were observed in IHD mortality in women and stroke mortality throughout the years (within variation).

Fig. 3 (Panel A) shows the SEI score ranking per province and region. The regions of San Miguelito, Panama and West Panama ranked as first, second and third, respectively, with the highest SEI scores. Darien ranked last, preceded by Bocas del Toro. Panel B shows the geographical distribution according to the SEI score. SEI scores were categorized into tertiles. The rationale behind this 

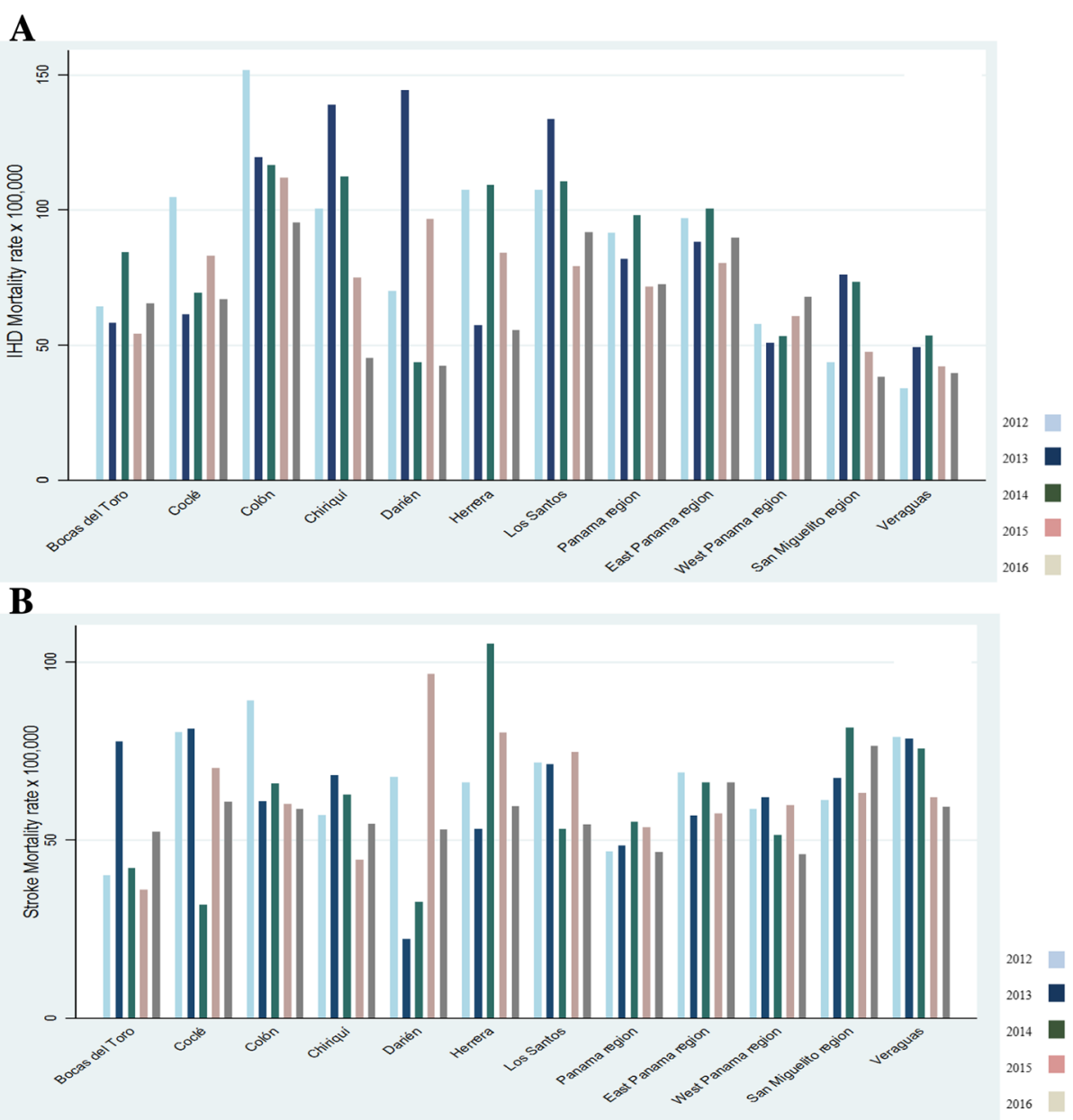

Fig. 1 Age-adjusted ischaemic heart disease (a) and stroke (b) mortality rates in men per province and region in Panama, 2012-2016

division was to observe if provinces with similar socioeconomic index had similar patterns with respect to the cardiovascular mortality rates. The lowest tertile was composed by Darién and Bocas del Toro. The middle tertile had Coclé, Veraguas, East Panama region, Chiriquí, Herrera, Los Santos and Colón whereas the highest tertile consisted of West Panama region, Panama region and San Miguelito region. When integrating the indigenous territories in the SEI, we observed that Emberá-Wounaan, Guna Yala and Ngöbe-Buglé were included in the lowest tertile. Darién and Bocas del Toro were recategorized to the middle tertile, while Colón was re-categorized to the highest tertile

Factorial analysis extracted the common factor (factor $1)$. This factor had the highest proportion (0.6044) compared to the other factors and therefore it was utilized. As shown in Table 2, the variable with the strongest correlation to factor 1 after rotation of factor loadings was years of education (0.9205), followed by social security access (0.8865). The overall Kaiser-Meyer-Olkin was
0.643, an acceptable value that indicates the correlation matrix is appropriate for factor analysis [23].

\section{Discussion}

We evaluated CVD mortality rates and SDH in eight provinces and four regions throughout 2012 to 2016. We observed geographical disparities in the SDH evaluated and in IHD mortality rates in men within the country. Temporal differences were seen in IHD mortality rates in women and stroke mortality rates. Furthermore, years of education and social security presented the strongest correlation with the SEI.

\section{Geographical and temporal variations in SEI and CVD mortality}

The constituent elements of our SEI index: income, education, and access to social security are key factors associated with health by being wholly or partially classed as social determinants [24-27]. Our results indicated regional disparities in $\mathrm{SDH}$ within the country, yet 

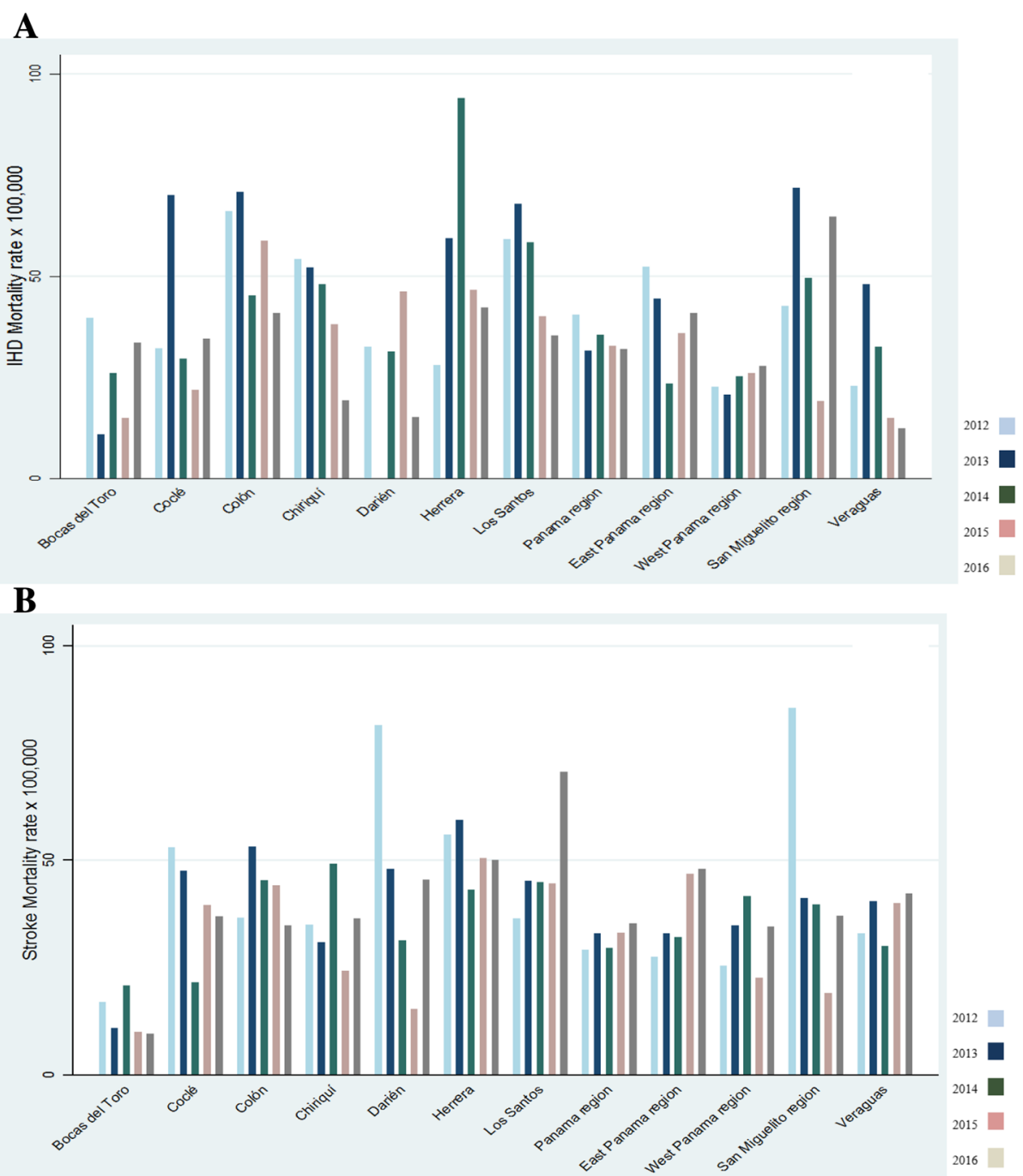

Fig. 2 Age-adjusted ischaemic heart disease (a) and stroke (b) mortality rates in women per province and region in Panama, 2012-2016

disparities between years were stable. Education, one of the most important determinants of health, presented the highest burden in our SEI index. In Panama, the current government expenditure on education represents $3.2 \%$ of the GDP, a low percentage compared to neighboring countries like Costa Rica (7.06\%), Cuba (12.83\%) and Chile (4.90\%) [28]. According to data from the World Bank, the government expenditure was $4.04 \%$ in the 1970s [28].

Although the average years of education was higher in women, the monthly income in men doubles the one of women. Similarly, a previous study using data from the HS concluded that men had an income $28 \%$ higher than women, despite men had higher rates of incomplete elementary and high school education [29]. In the context of these findings, gender-related policies need to be investigated-in depth. We found that social security coverage was $57-58 \%$ at a national level, a lower percentage than that reported by the INEC (an average of 75.5\% from 2012 to 2016) [30]. This discrepancy might be explained because during the HS, participants were asked if they have social security coverage the week prior the survey. In addition, there has been an increase in informal employment in the country, with $40.2 \%$ of the employed population in informal employment in 2016 [31]. Remarkably, the socioeconomic variable with the strongest correlation with the SEI was social security coverage when including the indigenous population. In agreement with our results, the MPI reported that in almost all indigenous territories, more than $90 \%$ of the population was multidimensional poor, followed by Bocas del Toro (45\%) and, Darién (40\%) [13].

Our results suggest that there was a decrease in mortality rates in IHD and stroke during the study period. Similarly, a recent study reported a decline in the trend of stroke mortality from 2001 to 2014 and a decrease in IHD mortality that started in 2010 [10]. Whether the decrease 


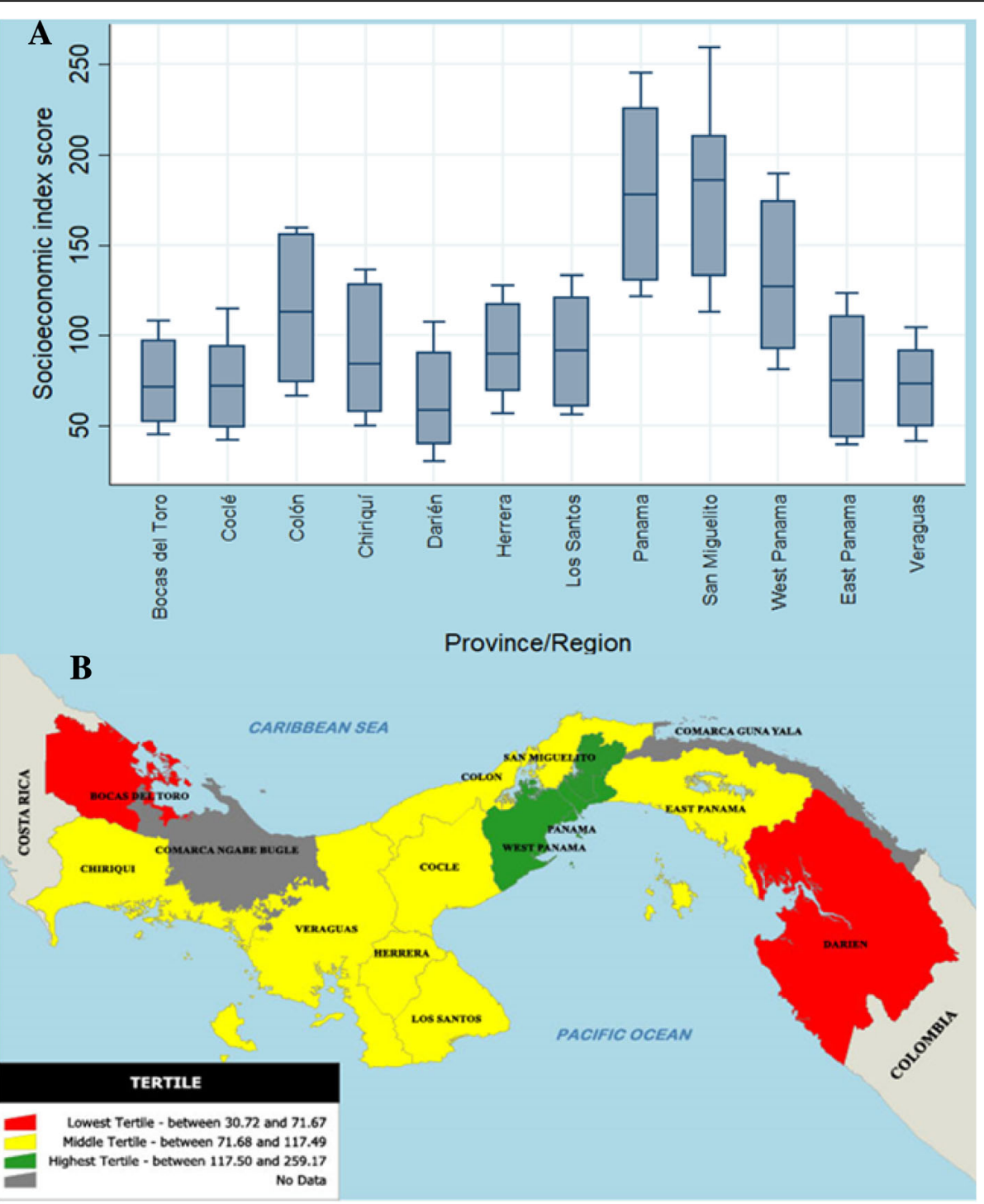

Fig. 3 Socioeconomic index score distribution per province and region in Panama. Map constructed at the Gorgas Memorial Institute using the softwares Manifold version 8.0.5 and Qgis version 2.8. Maps were developed using geographical coordinates from the National Institute of Statistics and Census (INEC, from its Spanish translation Instituto Nacional de Estadística y Censo). Panel a shows the SEl score ranking per province and region. Panel $\mathbf{b}$ shows the geographical distribution according to the SEl score

Table 2 Score coefficients extracted by principal-components method with ortogonal varimax rotation

\begin{tabular}{lll}
\hline Variables & Factor 1 & Kaiser-Meyer-Olkin \\
\hline Years of education & 0.9205 & 0.5996 \\
Social security access & 0.8865 & 0.5941 \\
Monthly income & 0.7728 & 0.8644 \\
Province/region & 0.4328 & 0.6300 \\
Overall & & 0.6430 \\
\hline
\end{tabular}

in trends occurred similarly in provinces and regions is less clear. Overall, we observed that mortality rates varied through years and provinces, especially mortality related to IHD. This variation could be explained, in part, by certifications of the cause of death, higher coverage of ambulance services since 2007 and greater availability of health services [32] . Less variation in mortality rates was found in the regions of Panama, West Panama and San Miguelito, possibly due to the proximity to tertiary care hospitals and better death registration and certification.

\section{Social determinants and IHD mortality}

For most of the years studied, Colon presented higher mortality rates for IHD in both women and men. 
Similarly, the highest mortality rate due to Diabetes Mellitus (DM) had been documented in this province [16]. This is despite the fact that Colon SEI score ranks above the middle tertile. Previous findings from a population-based study performed in Panama and Colon reported elevated prevalence of high blood pressure (HBP) among individuals with elementary education and illiteracy, compared to those with higher levels of education [33]. Colon, located $80 \mathrm{~km}$ from the capital city, is the third most populated province in the country with the largest African descent population [34]. Colon has a Free Trade Zone, the second largest in the world, several important maritime ports and part of the Panama Canal. GDP is the second in the country, superposed only by the province of Panama [35].

Colón has 74 health centers ( 1 secondary care hospital and 73 primary health care centers) [36]. Notably, more than half of the population of Colon had access to social security and therefore, it could be speculated that multiple factors may be playing an important role in the mortality rates observed in this province. Among the potential explanations, access and adherence to treatment deserves mention. In Colon, studies have reported that $65.6 \%$ of the population diagnosed with HBP were under antihypertensive treatment [33] and $72.2 \%$ of Colón's population cannot afford out-of pocket expenditure in the private sector of medications [37]. In agreement with our findings, higher CVD mortality rates have been reported in municipalities that are closer to the US-Mexico border, despite having superior infrastructure and proximity to health care [25], probably explained by US acculturation, unequal access to healthcare system or specific factors in the Mexican population living in the border area [25]. Further, ethnicity, as a proxy for biological characteristics and cultural norms has been associated with increase in cardiovascular risk factors [38].

\section{Social determinants and stroke mortality}

Los Santos and Herrera, with a known aging population, ranked in the middle tertile, and presented higher mortality rates for stroke, particularly in women. In line with our results, a study has reported higher self-reported prevalence of hypercholesterolemia, HBP, DM, and overweight in these provinces, but lower socioeconomic determinants [16].

Darién (with higher mortality rates for stroke in 2015 in men), was categorized in the lowest tertile of the SEI. Remarkably, Darién (along with indigenous territories) had lower amount of years of education (mean of 7 years), compared to the rest of the country. Mortality including premature mortality, increased with decreasing educational level and with increasing number of underlying diseases [24]. Similarly, there is evidence that socioeconomic risk factors may have a significant impact on stroke and mortality [26, 39]. Darien (located at the eastern end of the country-bordering Colombia) is an admixed population isolated by urban developments and limited of health public services. As of the year 2016, Darien had health centers from the $\mathrm{MoH}$, yet no hospitals. Noteworthy, in the mortality context, deaths are underreported in Darien by $52 \%$, therefore results must be interpreted with caution [28]. Interestingly, San Miguelito, a region with a high SEI index, albeit a high population density presented the highest stroke mortality rates in some years.

Several limitations must be addressed. First, we used socioeconomic variables that did not correspond to the individual's mortality data, so causality must not be inferred and the present findings must be interpreted with caution, in order to avoid an ecological fallacy. Second, to avoid bias, we excluded indigenous territories from data panel analysis. Of note, the NMR underreporting is still an important limitation in indigenous territories. In the HS, socioeconomic variables were obtained from indigenous territories, however, because of social inequality; socioeconomic determinants in the indigenous territories differed importantly compared to other regions. When integrating this data in the factorial analysis and obtaining the SEI, the other regions had an overestimated SEI, limiting the comparisons in these regions. Finally, only five years were considered in the study because since 2012, the HS had a mayor variation in the sampling, and thus trend analysis was not applicable. However, to the best of our knowledge, this is the first study that attempts to explore CVD mortality in relation to socioeconomic determinants per province and region in Panama.

\section{Conclusion}

We observed geographical and temporal disparities in socioeconomic determinants and CVD mortality rates. Total years of education had the strongest correlation with the (SEI), if we excluded the indigenous territories. However, if we included the indigenous territories, social security coverage had the strongest correlation with the SEI demonstrating the importance of access to health care. Further epidemiological studies aimed to disentangle the role of risk factors for IHD mortality in Colón are warranted. As for Los Santos, Herrera, San Miguelito and Darien, SDH in relation to mortality deserve to be investigated in-depth.

Panama has a multiethnic population with cultural diversity per region, a key aspect to consider when developing strategies and interventions to reduce health inequalities. In this perspective, political interventions with a multisectorial approach must be achieved in order to decrease the uneven distribution of $\mathrm{SDH}$ throughout the country. Additional, our study supports the need of validated socioeconomic data and the notion of an integrated register health system. 


\section{Additional files}

Additional file 1: Baseline characteristics of the household survey per province and region based on expanded data. The table shows the distribution of age mean, social security coverage, income mean and years of education mean by provinces and years analyzed in the present study. (DOCX 58 kb)

Additional file 2: Variation in socioeconomic variables and cardiovascular disease mortality rates. The table shows the variations in all the socioeconomic variables and $\mathrm{HDD} /$ stroke mortality in men and women throughout the provinces and regions (between) and throughout the years (within variation). (DOCX $16 \mathrm{~kb}$ )

\section{Abbreviations}

CVD: Cardiovascular disease; DM: Diabetes Mellitus; GDP: Gross domestic product; HBP: High blood pressure; HS: Household survey; ICD10: International Classification of Diseases tenth revision; IHD: Ischaemic heart disease; INEC: National Institute of Statistics and Census, from its Spanish translation Instituto Nacional de Estadística y Censo); LA: Latin America; MPI: Multidimensional Poverty Index; NMR: National Mortality Register; OECD: Organization for Economic Co-operation and Development; PISA: Programme for International Student Assessment; PREFREC: Survey on Risk Factors Associated With Cardiovascular Disease, from its Spanish translation Prevalencia de Factores de Riesgo de Enfermedad Cardiovascular); SD: Standard deviation; SDH: Social Determinants of Health;

SEl: Socioeconomic index; TERCE: Third Regional Comparative and Explanatory Study; UNESCO: United Nations Educational, Scientific and Cultural Organization; WHO: World Health Organization

\section{Acknowledgements}

The authors would like to acknowledge the work of Cecilio Niño with the maps and figures, Franz Castro and María Teresa Carrión for their mortality data algorithms and Emerson Córdoba and the personnel from INEC, for their support and availability concerning the NMR and the HS.

\section{Funding}

This research received no specific grant from any funding agency in the public, commercial or not-for-profit sectors. IMV is supported by the Sistema Nacional de Investigación (SNI, SENACYT). The funding sources had no involvement in the study design, writing of the report or in the decision to submit the article for publication.

\section{Availability of data and materials}

The data that support the findings of this study are available from INEC but restrictions apply to the availability of these data, which were used under license for the current study, and so are not publicly available. Data are however available from the authors upon reasonable request and with permission of INEC. Population estimates and projections used for the analyses are available from INEC at: https://www.contraloria.gob.pa/inec/ Publicaciones/Publicaciones.aspx?ID_SUBCATEGORIA $=10$ \&ID_PUBLICACION=491\&ID_IDIOMA=1\&ID_CATEGORIA=3

\section{Authors' contributions}

LQ curated, analyzed and interpreted the data, did the research and wrote the draft of the work. VHB analyzed and interpreted the data and critically revised the draft for important intellectual content, IMV analyzed and interpreted the data, did the research, wrote the draft of the work and critically revised the draft for important intellectual content, BG and JM designed and supervised the work and critically revised the draft for important intellectual content. Final approval of the version to be published was given by $L Q, V H B, I M V, B G$ and $J M$. All the authors agree to be accountable for all aspects of the work in ensuring that questions related to the accuracy or integrity of any part of the work are appropriately investigated and resolved.

\section{Ethics approval and consent to participate}

The data utilized for the present study is in the public domain and did not contain sensitive information (anonymous secondary data), consequently no ethics approval was required. Permission to have access to the variables utilized from the Household survey was obtained from the National
Comptroller (Contraloría General de la República), head of the National Institute of Statistics and Census.

\section{Consent for publication}

Not applicable.

\section{Competing interests}

The other authors declare that they have no competing interests.

\section{Publisher's Note}

Springer Nature remains neutral with regard to jurisdictional claims in published maps and institutional affiliations.

\section{Author details}

${ }^{1}$ Gorgas Memorial Institute for Health Studies, Panama City, Panama. ${ }^{2}$ National Secretariat for Science and Technology, Panama City, Panama. ${ }^{3}$ Department of Research and Health Technology Assessment."Gorgas Memorial Institute for Health Studies, Panama City, Panama.

Received: 19 June 2018 Accepted: 4 February 2019

Published online: 15 February 2019

\section{References}

1. World Health Organization. Available at: http://www.who.int/mediacentre/ factsheets/fs317/en/. Accessed 16 Feb 2018

2. Collaborators GBDCoD. Global, regional, and national age-sex specific mortality for 264 causes of death, 1980-2016: a systematic analysis for the global burden of disease study 2016. Lancet. 2017;390(10100):1151-210.

3. Mozaffarian D, Benjamin EJ, Go AS, Arnett DK, Blaha MJ, Cushman M, et al. Heart disease and stroke statistics--2015 update: a report from the American Heart Association. Circulation. 2015;131(4):e29-322.

4. Stringhini S, Carmeli C, Jokela M, Avendano M, Muennig P, Guida F, et al. Socioeconomic status and the $25 \times 25$ risk factors as determinants of premature mortality: a multicohort study and meta-analysis of 1.7 million men and women. Lancet. 2017;389(10075):1229-37.

5. Oudin Astrom D, Sundquist J, Sundquist K. Differences in declining mortality rates due to coronary heart disease by neighbourhood deprivation. J Epidemiol Community Health. 2018.

6. Ferrario MM, Veronesi G, Kee F, Chambless LE, Kuulasmaa K, Jorgensen $T$, et al. Determinants of social inequalities in stroke incidence across Europe: a collaborative analysis of 126635 individuals from 48 cohort studies. J Epidemiol Community Health. 2017;71(12):1210-6.

7. Fernando L, Pamela S, Alejandra L. Cardiovascular disease in Latin America: the growing epidemic. Prog Cardiovasc Dis. 2014;57(3):262-7.

8. World Economic Forum. Latin America is the world's most unequal region Here's how to fix it, January 2016. Available at: https://www.weforum.org/ agenda/2016/01/inequality-is-getting-worse-in-latin-america-here-s-how-tofix-it/. Accessed 16 Feb 2018

9. National Institute of Statistics and Census. Republic of Panama. Estimaciones y Proyecciones de la población indígena por provincia, comarca, , según sexo y edad: años 2010-20. Available at: https://www.contraloria.gob.pa/ inec/archivos/P6751Bolet\%C3\%ADn\%2018. \%20ESTIMACIONES\%20Y\%20PROYECCIONES.pdf. Accessed 23 Feb 2018

10. Carrion Donderis M, Moreno Velasquez I, Castro F, Zuniga J, Gomez B, Motta J. Analysis of mortality trends due to cardiovascular diseases in Panama, 2001-2014. Open heart. 2016;3(2):e000510

11. Instituto Conmemorativo Gorgas de Estudios de la Salud. Sistema de información Geográfico de Enfermedades Cardiovasculares y Diabetes en Panamá. 2015 [Internet]. Panamá: Departamento de Investigación y Evaluación de Tecnología Sanitaria; c2000-2013 [actualizado 2015 Jul 30; citado 08 ene 18]. Available at: http://www.gorgas.gob.pa/ SiGCARDIOVASCULARES/Inicio.htm

12. The World Bank. Available at: https://data.worldbank.org/indicator/SI.POV. GINI?locations=PA\&view=chart. Accessed 19 Feb 2018.

13. Ministery of Economy and Finance Multidimensional Poverty Index. Available at: http://www.mef.gob.pa/es/informes/Documents/Informe\% 20del\%20Indice\%20de\%20Pobreza\%20Multidimensional\%20de\%20 Panama\%202017.pdf. Accessed 10 Dec 2018.

14. Castro F, Shahal D, Tarajia M, Velasquez IM, Causadias MT, Herrera V, et al. Baseline characteristics, survival and direct costs associated to treatment of gastric cancer patients at the National Oncology Institute of Panama from 
2012 to 2015: a hospital-based observational study. BMJ Open. 2017;7(9): e017266.

15. Moreno Velasquez I, Castro F, Gomez B, Cuero C, Motta J. Chronic kidney disease in Panama: results from the PREFREC study and National Mortality Trends. Kidney international reports. 2017;2(6):1032-41.

16. Motta JA, Ortega-Paz LG, Gordon CA, Gomez B, Castillo E, Herrera Ballesteros V, et al. Diabetes mortality in Panama and related biological and socioeconomic risk factors. Rev Panam Salud Publica. 2013;34(2):114-20.

17. Collaborators GBDM. Global, regional, and national under-5 mortality, adult mortality, age-specific mortality, and life expectancy, 1970-2016: a systematic analysis for the global burden of disease study 2016. Lancet. 2017;390(10100):1084-150.

18. Mikkelsen L, Phillips DE, AbouZahr C, Setel PW, de Savigny D, Lozano R, et al. A global assessment of civil registration and vital statistics systems: monitoring data quality and progress. Lancet. 2015;386(10001):1395-406.

19. Mustafa MH, Mukhtar AM. Factors associated with antenatal and delivery care in Sudan: analysis of the 2010 Sudan household survey. BMC Health Serv Res. 2015;15:452.

20. Hancioglu A, Arnold F. Measuring coverage in $\mathrm{MNCH}$ : tracking progress in health for women and children using DHS and MICS household surveys. PLoS Med. 2013;10(5):e1001391.

21. National Institute of Statistics and Census. Republic of Panama. Household Survey Available at: https://www.contraloria.gob.pa/inec/Publicaciones/ Subcategoria.aspx?ID_SUBCATEGORIA=38\&ID_IDIOMA=1. Accessed $10 \mathrm{Dec}$ 2018.

22. National Institute of Statistics and Census. Republic of Panama. Available at: https://www.contraloria.gob.pa/inec/archivos/P6001Comentarios.pdf. Accessed 9 May 2018

23. Jean Pierre Lévy Mangin JVM. Analisis Multivariable Para Las Ciencias Sociales. España2003.

24. Lund Jensen N, Pedersen HS, Vestergaard M, Mercer SW, Glumer C. Prior a The impact of socioeconomic status and multimorbidity on mortality: a population-based cohort study. Clin Epidemiol. 2017;9:279-89.

25. Anaya G, Al-Delaimy WK. Effect of the US-Mexico border region in cardiovascular mortality: ecological time trend analysis of Mexican border and non-border municipalities from 1998 to 2012. BMC Public Health. 2017; 17(1):400.

26. Carlsson AC, Li X, Holzmann MJ, Arnlov J, Wandell P, Gasevic D, et al. Neighborhood socioeconomic status at the age of 40 years and ischemic stroke before the age of 50 years: a nationwide cohort study from Sweden. Int J Stroke. 2017;12(8):815-26.

27. Kaplan GA, Keil JE. Socioeconomic factors and cardiovascular disease: a review of the literature. Circulation. 1993;88(4 Pt 1):1973-98.

28. World Bank. Available at: https://data.worldbank.org/indicator/SE.XPD.TOTL. GD.ZS?locations=PA\&view=chart. Accessed on December 2018.

29. Autoridad de Protección al Consumidor y Defensa de la Competencia. Perfiles de Ingresos y Retornos de la Educación en Panamá. Available at: http://www.acodeco.gob.pa/acodeco/uploads/pdf/publicaciones_estudios/ NT_22_-_RETORNOS_DE_LA_EDUCACION_EN_PANAMA.09_04_2009_09_ 13_15_a.m..pdf. Accessed 11 Mar 2018.

30. ational Institue of Statistics ans Census. Republic of Panama. Available at: https://www.contraloria.gob.pa/inec/Publicaciones/Publicaciones.aspx?ID_ SUBCATEGORIA=36\&ID_PUBLICACION=840\&ID_IDIOMA=1\&ID_CATEGORIA= 5 Accessed 8 Feb 2018.

31. National Institute of Statistics and Census. Republic of Panama. Available at: https://www.contraloria.gob.pa/inec/archivos/P7851441-07.pdf. Accessed 26 Feb 2018.

32. Ministry of Health. Informe Anual del Recurso Humano en Salud de Panamá. Available at: http://www.minsa.gob.pa/sites/default/files/ publicacion-general/informe_anual_del_recurso_humano_en_salud_rhs_ panama_2014.pdf. Accessed 6 Mar 2018.

33. Mc Donald Posso AJ, Motta Borrel JA, Fontes F, Cruz Gonzalez CE, Pachon Burgos AA, Cumbrera Ortega A. High blood pressure in Panama: prevalence, sociodemographic and biologic profile, treatment, and control (STROBE). Medicine. 2014;93(22):e101

34. Perego UA, Lancioni $H$, Tribaldos $M$, Angerhofer $N$, Ekins JE, Olivieri $A$, et al. Decrypting the mitochondrial gene pool of modern Panamanians. PLoS One. 2012;7(6):e38337.

35. Ministery of Economy and Finance Available at: http://www.mef.gob.pa/es/ noticias/Documents/Diagnostico\%20socioeconomico\%20de\%20la\%2 Oprovincia\%20de\%20Colon\%202016.pdf. Accessed 10 Dec 2018.
36. Ministry of Health. Lista de Instalaciones de Salud Año 2014. Availabe at: http://www.minsa.gob.pa/sites/default/files/publicacion-general/listado_de instalaciones_de_salud_ano_2014.pdf. Accessed 26 Feb 2018.

37. Herrera Ballesteros VH. Perfil Del Gasto De Bolsillo En Medicamentos Esenciales En Panama, 2014. Value Health. 2015;18(7):A814.

38. Howard G, Lackland DT, Kleindorfer DO, Kissela BM, Moy CS, Judd SE, et al. Racial differences in the impact of elevated systolic blood pressure on stroke risk. JAMA Intern Med. 2013;173(1):46-51.

39. Amarenco P, Abboud H, Labreuche J, Arauz A, Bryer A, Lavados PM, et al. Impact of living and socioeconomic characteristics on cardiovascular risk in ischemic stroke patients. Int J Stroke. 2014;9(8):1065-72.
Ready to submit your research? Choose BMC and benefit from:

- fast, convenient online submission

- thorough peer review by experienced researchers in your field

- rapid publication on acceptance

- support for research data, including large and complex data types

- gold Open Access which fosters wider collaboration and increased citations

- maximum visibility for your research: over $100 \mathrm{M}$ website views per year

At $\mathrm{BMC}$, research is always in progress.

Learn more biomedcentral.com/submissions 